\title{
CORPOS, IDENTIDADE E FOTOGRAFIA NA MODERNIDADE DIGITAL
}

\author{
Rodrigo Duarte Ferrari' \\ André Marsiglia Quaranta? \\ Antonio Luis Fermino ${ }^{3}$ \\ Ângelo Luiz Brüggemann ${ }^{4}$
}

RESENHA

[BASTOS, Larissa Grandi Vaitsman. Corpografias: entre o analógico e o digital. 2008. Tese (Doutorado em Comunicação). Rio de Janeiro, Programa de Pós-Graduação em Comunicação, Universidade Federal do Rio de Janeiro.

\section{RESUMO}

Mídia, fotografia, corpo e identidade feminina são os quatro eixos que a autora da tese Corpografias: entre o analógico e o digital utiliza para refletir sobre o processo de construção da identidade na pós-modernidade. Nesse contexto, realizamos uma resenha sobre a tese com o objetivo de abrir um diálogo entre as contribuições desta produção com o campo da mídia-educação física, assim como questionar a utilização do termo pós-modernidade para caracterizar a sociedade e cultura contemporânea.

Palavras Chaves: Mídia, fotografia, corpo, identidade

1 Mestre em Educação Física (PPGEF/UFSC) e doutorando em Educação no PPGE/CED/UFSC.

Contato: rd.ferrari@gmail.com.

2 Mestre em Educação Física (PPGEF/UFSC), professor da rede pública estadual de Sergipe (SEED/SE). Contato: andrequaranta@gmail.com.

3 Mestrando em Educação no PPGE/CED/UFSC. Contato: antonioluisf@gmail.com.

4 Acadêmico do curso de licenciatura em Educação Física/UFSC, bolsita PIBIC/CNPq/UFSC.

Contato: angelobruggemann@gmail.com. 


\section{INTRODUÇÃO}

Em sua tese de doutorado, Bastos (2008) reflete sobre as consequências da transição tecnológica, do analógico para o digital, vinculadas às Tecnologias de Informação e Comunicação (TICs), na construção de um novo ideal de beleza feminino que começa a se desenhar no início do século $X X I^{5}$. Segundo a autora, as imagens digitalizadas e veiculadas na mídia, sobretudo, as com interesses mercadológicos associados à indústria estética, são facilmente manipuláveis por ferramentas como o photoshop ${ }^{6}$ e são responsáveis pela criação de padrões de beleza artificiais e inalcançáveis para a maioria das mulheres.

Por sua vez, esses padrões digitais se tornam desejos de consumo e atingem com eficácia as metas da indústria estética, que vende desde produtos cosméticos até a necessidade das mulheres de se submeterem à intervenções cirúrgicas. Por exemplo, as populares próteses de mama de silicone. Bastos (2008) também afirma que esse movimento é responsável pelo crescimento de distúrbios psicológicos, como a anorexia.

Fotografia, mídia e corpo são as três bases que sustentam a hipótese da tese de Bastos (2008), em que o fenômeno de desmaterialização ${ }^{7}$ do corpo provocado pelo digital e os processos de globalização ${ }^{8}$ são as novas forças que regem a construção da identidade feminina pós-moderna e o novo ideal de beleza no século XXI. A tese da autora está dividida em quatro capítulos, em que ela apresenta suas reflexões para argumentar a favor de sua hipótese. No primeiro capítulo, a mídia é o foco de suas reflexões, em seguida a linguagem fotográfica assume a centralidade das discussões. No terceiro capítulo, o corpo se torna o foco de seu trabalho, e por fim, a autora encerra suas argumentações refletindo sobre a identidade feminina.

A tese de Bastos (2008) nos chamou a atenção pelo tema de suas reflexões na intersecção dos campos da comunicação e da educação física, pois as relações entre o corpo e a mídia despertam nossos interesses pedagógicos relativos a essa temática.

Escolhemos a tese de Bastos (2008) a partir de um estudo exploratório na forma de um levantamento das teses e dissertações, publicadas e disponíveis para acesso na internet, da área de comunicação que poderiam dialogar com o campo da educação física. Neste conjunto elegemos, a tese Corpografias: entre o analógico e o digital de Larissa Grandi Vaitsman Bastos (2008), defendida na Universidade Federal do Rio de Janeiro, sob a orientação da Dra. Nízia Maria Souza Villaça como o trabalho que seria o objeto de nosso estudo. O críterio de

5 Esse estudo foi realizado como tarefa didática da disciplina Seminário de Aprofundamento em Pesquisa em Educação Física, Mídia e Tecnologias, desenvolvida no $3^{\circ}$ trimestre/2011 no Programa de Pós-Graduação em Educação Física (PPGEF) da Universidade Federal de Santa Catarina (UFSC), pelos professores Dr. Giovani De Lorenzi Pires e Fernando Gonçalves Bitencourt.

6 Software que possui como característica a edição de imagens.

7 Bastos (2008) não define o significado dessa palavra no contexto de sua pesquisa, porém interpretamos que a autora se refere à característica dos objetos digitais, formados por bits de informação e que precisam de algum aparelho eletrônico para se materializar. Por exemplo, a fotografia analógica é a representação de uma imagem que é inscrita no filme fotográfico, por outro lado, a fotografia digital é uma representação de uma imagem em bits de informação.

8 Bastos (2008) também não define a que se refere com a palavra globalização, porém interpretamos que ela seja ao processo de globalização da economia, nesse caso, fazemos essa leitura a partir das descrições do sociólogo Castells (2010). 
escolha foi nosso interesse em dialogar com a temática da tese, sobertudo, a relação entre o corpo, as TICs e a opção teórica da autora.

Após a realização de um estudo detalhado sobre a tese de Bastos (2008), focalizamos nossas reflexões na opção da autora em utilizar o conceito pós-modernidade para representar o contexto social e cultural de sua pesquisa. Dessa forma, nosso foco de investigação é abrir um diálogo com a tese de Bastos (2008) e refletir sobre a mídia, a linguagem fotográfica e a identidade feminidade em meio as tensões e limites da noção de ruptura pós-moderna.

No resumo da tese, Bastos (2008) anuncia objetivamente essa escolha: "A escrita do corpo na pós-modernidade e sua desmaterialização no trânsito entre os paradigmas analógicos e digitais, integrados pelos processos de globalização, compõem a hipótese desenvolvida neste trabalho" (BASTOS, 2008 - grifo dos autores desta resenha). Com isso, questionamos se é possível identificar na tese de Bastos (2008) os aspectos que objetivam um ruptura entre a modernidade $\mathrm{e}$ a pós-modernidade em meio a essa transição do analógico para o digital? Com base nesse questionamento, objetivamos refletir sobre a fotografia, a mídia e o corpo a partir de uma leitura mídia-educativa ${ }^{9}$ da tese de Bastos (2008) direcionada para o campo reflexivo e prático da educação física.

\section{MÍDIA, FOTOGRAFIA, CORPO E IDENTI- DADE FEMININA}

Desde a revolução de Gutenberg com a invensão da prensa móvel para reproduzir em larga escala livros e outros conteúdos impressos que a mídia se tornou um dos elementos centrais da organização social e cultural moderna. Nesse caso, o papel se tornou o primeiro meio capaz de fazer com que a informação circulasse nas sociedades europeias do século XV. No século $X X$, o processo de circulação da informação atingiu outros patamares, com as invenções do rádio, cinema e televisão. Segundo Bastos (2008), esses meios de comunicação estão associados com o paradigma analógico e ainda fazem parte da modernidade.

Antes da internet, a informação era produzida e veiculada exclusivamente por profissionais e organizações especializadas nessa tarefa, enquanto a recepção era destinada aos cidadãos consumidores. Essa lógica funciona para as mídias impressas, radiofonicas e audiovisuais. Entretanto, com a consolidação da internet, essa lógica perdeu a nitidez dos contornos que definiam as fronteiras que separavam os comunicadores dos receptores. Na internet qualquer cidadão com acesso à internet é um receptor e um comunicador global em potencial:

O sistema de comunicação, portanto, não se situa na tradição mecanicista do séc. XIX (um emissor que remete uma mensagem a um destinatário) e talvez nem na tradição cibernética (na qual através do feedback ou retroatividade - o sistema se torna complexo e circular). O texto visual deve ser visto como resultado de um contexto inquieto que envolve sempre esses três participantes, cada qual com seus papéis duplos de observados e observadores: autor, informante e espectador são atores do processo comunicativo (CANEVACCI citado por BASTOS, 2008).

9 O conceito de Mídia-Educação (BELLONI, 2001; FANTIN, 2006), utilizando elementos dos campos da educação e da comunicação, tem por objetivo a formação do sujeito crítico diante das linguagens midiáticas. 
Bastos (2008) continua e reflete sobre essas relações de comunicação com o auxílio de Baudrillard, que estabelece relações entre a sedução, as imagens digitais e o consumo no mundo globalizado. A autora cita o papel da fotografia na publicidade para atingir os interesses mercadológicos e da fotografia no jornalismo como meio para legitimar os discursos sobre a verdade objetiva das informações.

É nesse contexto que a autora situa a relação entre o desejo e a linguagem fotográfica como aspectos centrais no jogo de criação e definição de novas indentidades na pós-modernidade. Além da linguagem fotográfica, Bastos (2008) afirma que a moda e suas constantes mutações também exercem forte influência nesses processos vinculados à identidade do sujeito pós-moderno:

Para Hall (2003:12-3), classificar e definir o sujeito pós-moderno é tarefa complexa. Diferente do sujeito iluminista, "centrado, unificado, dotado das capacidades de razão, de consciência e de ação, cujo centro consistia num núcleo interior",(HALL:2003:10) ou do sujeito sociológico, cujo núcleo interior não era autônomo e auto-suficiente, mas era formado na relação "com outras pessoas importantes para ele", (HALL:2003:11) o atual se classifica exatamente pela não permanência e pela extrema flexibilidade, tornando-se mais "provisório, variável e problemático" (HALL:2003:12) (BASTOS, p. 33, 2008)

Em meio a essa fragmentação da identidade do sujeito moderno e da busca ou reflexões sobre novas possibilidades de multiplas identidades pós-modernas, Bastos (2008) interpreta o papel da internet no início do século XXI com uma imagem do próprio fim da modernidade. A internet e a linguagem fotográfica são interpretados pela autora como parte de uma realidade totalmente reificada, onde a crítica e a autonomia dos sujeitos não são mais possíveis: "Independente da exibição consentida, vemo-nos sujeitos a um sistema cada vez mais aperfeiçoado de controle, no qual diversos tipos de dispositivos de vigilância nos acompanham e revelam a cada minuto" (BASTOS, p. 48, 2008).

Para a autora, a fotografia é um dos aspectos centrais desse sistema social de controle e ela ainda afirma que a formação da identidade do sujeito pós-moderno está ligada com a linguagem fotografica, principalmente, na transição do analógico e para o digital. No âmbito da fotografia digital, afirma Bastos (2008) que as possibilidades produtivas e a circulação das imagens são características pós-modernas.

A transição para o paradigma digital gerou blocos distintos, os que aceitam e os que não concordam com as inovações tecnológicas na produção das fotografias. Levando em consideração que a fotografia é uma linguagem, de acordo com Bastos (2008, p. 75), “a manipulação e o manejo do processo permanecem, em essência, sem significativas mudanças". O que está em voga é entender que houve modificações - além das físicas como extinção dos filmes - da seguinte ordem:

Elas aconteceram e abalaram de maneira significativa a produção fotográfica, principalmente no que diz respeito ao princípio de captação da imagem, à ética profissional, à relação com o tempo e ao fluxo das imagens, além da preocupação com os métodos de armazenamento, que devem garantir que, dentro de algumas décadas, ainda poderemos contar com uma memória iconográfica preservada tanto em nível pessoal quanto público (BASTOS, 2008, p. 75). 
A questão que Bastos (2008) mais específica nesta transição para o paradigma digital, reside nas possibilidades manipulativas das imagens, o que é refletido a partir do momento em que a fidedignidade e correspondência dos fatos como realmente aconteceram fica comprometida, porém a autora não despreza que esta possibilidade não estivesse presente na perspectiva analógica. Essa condição é potencializada com o crescimento da internet, que gera uma nova dinâmica de produção, veiculação e compartilhamento de imagens fotograficas.

A autora entende que na pós modernidade "a relação entre o sujeito e seu próprio corpo - assim como o corpo do outro" (BASTOS, 2008, p. 103) não é mais decisiva que em outros tempos. Pois há uma desmaterialização dos corpos, a partir do momento em que se tornam virtuais, enfatizando que na sociedade atual o corpo é a principal atração. Corpo este que foi pasteurizado por uma indústria estética, que padronizou um ideal de corpo para as mulheres.

$\mathrm{Na}$ atualidade, para Bastos (2008), o corpo passou a ser um identificador/ formador de determinados grupos sociais, que se juntam pela forma de seus shape, "deslocando-nos do eixo das relações humanas na concepção mais tradicional, concentrando-nos, de certa forma, no que se vê, no que se apresenta, e não no que realmente nos foi determinado" (p. 105). Isto induz os sujeitos a buscarem um corpo perfeito, os mesmos corpos que são divulgados e construídos pela mídia:

São, de fato, as representações nas mídias e publicidade que têm o mais profundo efeito sobre as experiências do corpo. São elas que nos levam a imaginar, a diagramar, a fantasiar determinadas existências corporais, nas formas de sonhar e de desejar que propõem (SANTAELLA 2004 citado por BASTOS, 2008, p. 108).

Relacionado a esse corpo pós-moderno convertido em imagens, Bastos (2008), reflete sobre a construção da identidade feminina e utiliza o conceito de identidade volátil proposta por Hall (2002).

Com este conceito de identidade a autora compreende a identidade das mulheres como algo em transformação constante, porém, à procura da manutenção do "jovem". Esta procura se dá pela necessidade das mulheres serem percebidas e não somente se perceberem, fazendo com que seus corpos se tornem a sua identidade na procura de um reconhecimento.

Para Hall (2000,p.13), “a identidade plenamente unificada, completa, segura e coerente é uma fantasia". Pois estamos inseridos em um universo de significações e representações culturais na qual se multiplicam e somos confortados por identidades que nos cabem em determinados momentos. Porém, contraditoriamente as mulheres, salvo algumas exceções, estão em busca do mesmo padrão.

A autora apresenta o livro de 30 anos da Playboy que demonstra esta procura da igualdade dos corpos com o passar dos anos, lá nos anos 70 era perceptível as diferença entre os corpos das mulheres, cada um com sua identidade, e que nos tempos atuais só se muda a pessoa pois os corpos são todos semelhantes sem uma identidade destacável (p.141).

Estes corpos sem identidade ou com identidade global podem ser pensados como uma sociedade consumista que se sente na necessidade de "ter" algo novo e não "ser" o novo. Tendo em vista que o 
mercado da moda que é o grande influenciador desta identidade, é constantemente atualizado e consumido sem nenhuma reflexão crítica quanto ao assunto de identidade cultural.

Na quarta parte do seu trabalho, um tópico apresenta as questões de identidade, sendo oferecido ao leitor um recorte histórico sobre a evolução das revistas femininas que influenciam muito em como as mulheres devem se comportar, se vestir e estar fisicamente. "As revistas femininas são, da mesma forma, palco para a exibição daquilo que se constata como eco e consequência dos padrões midiáticos percebidos em nossa sociedade de consumo e do espetáculo" (Bastos, 2008, p.149).

\section{CONSIDERAÇÕES FINAIS}

Em síntese, Bastos (2008) argumenta que na transição paradigmática do analógico para o digital, a fotografia digital de corpos, cuja imagens são facilmente manipuláveis, se destaca como linguagem jornalística e publicitária que influencia a construção da identidade feminina no sécuo XXI. Esse processo ocorre com a padronização e veiculação de um ideal de beleza corporal feminino pelos meios de comunicação, com destaque para a internet, um meio com características diferentes de produção e consumo de informações. Até esse momento, concordamos com as reflexões críticas da autora, contudo, não identificamos em seu trabalho uma argumentação consistente que justifique o uso da expressão pós-moderno. A pós-modernidade anunciaria o fim da modernidade e a inauguração de uma nova sociedade e uma nova cultura.

Apesar de não estar explicito em sua tese, Bastos (2008) se refere à pósmodernidade com enfase no contexto social da economia, do qual faz parte a mídia, e exercendo seu poder via os artifícios da publicidade. Segundo Rouanet (1987), o sistema econômico capitalista é uma das esferas sociais que definem a modernidade ${ }^{10}$ em torno da organização racional dos processos de produção, da existência de um força de trabalho livre, no cálculo contábil e na utilização de técnicas científicas para aumentar a produtividade. Em outras palavras, essa descrição representa o que se identificou como sociedades ocidentais industrializadas e apesar de algumas vairiantes, os adeptos da pós-modernidade argumentam a favor da existência de modificações nessa estrutura que caracteriza uma ruptura. É dessa perspectiva que surge as denominações de sociedades pós-industriais e globalizadas.

O fato é que não há dúvida de que o capitalismo se transformou, mas também não há dúvida que essas modificações não são suficientes para descaracterizar ou substituir por outras relações as características do capitalismo descritas por Rouanet (1987). Para o autor o equivoco dos teóricos da pós-modernidade é confundir as transformações tecnológicas com o âmbito das relações sociais. Definitivamente, a internet

10 Rouanet (1987) escreve no artigo A verdade e a ilusão do pós-moderno os limites das tentativas teóricas de definir uma ruptura entre a modernidade e a pós-modernidade. O autor desenvolve seus argumentos com base na definição webweriana de modernidade social (estado e economia) e cultural (saber, moral e arte). Porém, nessa resenha vamos nos concentrar apenas na discussão econômica, por ela se destacar na tese de Bastos (2008) e por uma questão de delimitação de nossas reflexões. 
é uma revolução tecnológica dos meios de comunicação, contudo, essa revolução ainda não desencadeou mudanças profundas que caracterizem novas relações sociais hegemônicas:

Assim como não foi a máquina a vapor que iniciou o capitalismo, mas um novo tipo de relações sociais, não será o computador de quinta geração que vai acabar com o capitalismo, e sim uma mudança nas relações sociais (ROUANET, 1987, p. 259).

Apesar desses limites na identificação de uma ruptura definitiva no sistema econômico capitalista, destacamos que o mesmo se transformou ao ponto de se tornar uma complexa rede global de negócios multinacionais. Isso gera consequencias que são muito bem observadas e analisadas por Bastos (2008), pois a globalização exerce uma força que tende à padronização de um ideal de beleza do corpo feminino, que se torna ainda mais mercadoria a ser consumida, tanto pelas mulheres como pelos homens. Soma-se a esse contexto, a transformação relacional dos individuos com as fronteiras nacionais e o enfraquecimento da identidade nacional. Porém, nesse caso estamos no máxímo descrevendo a intensificação da crítica realizada por Adorno e Horkheimer sobre a própria modernidade a partir do conceito de indústria cultural:

Sua ideologia é o negócio. A verdade em tudo isso é que o poder da indústria cultural provém de sua identificação com a necessidade produzida, não da simples oposição a ela, mesmo que se tratasse de uma oposição entre a onipotência e impotência (ADORNO; HORKHEIMER, 1985, p. 113).

A necessidade produzida pela mídia com a ajuda da linguagem fotográfica digital contemporanea descrita e analisada por Bastos (2008) é a mesma do início do século XX. Os argumentos da autora não superam e nem diferem do conteúdo do capítulo

A Indústria Cultural: o Esclarecimento como Mistificação das Massas (ADORNO; HORKHEIMER, 1985) que foi publicado em 1947. Inclusive, pelo que entendemos, a autora radicaliza os efeitos da lógica da indústria cultural e valoriza ainda mais a integração das subjetividades à esse modelo, a despeito das possibilidades de resistência frente aos interesses mercadológicos da indústria cultural.

O corpo que se desmaterializa e se transforma em imagem digital manipulada é apenas uma variação dos efeitos cinematográficos hollywoodianos e a criação artificial de suas musas, sempre exploradas pelos interesses publicitários. Para os consumidores só restam duas opções: "participar ou omitir-se" (ADORNO; HORKHEIMER, 1985, p. 122):

O efeito, o truque, cada desempenho isolado e repitível foram sempre cúmplices da exibição de mercadorias para fins publicitários, atualmente todo close de uma atriz de cinema serve de publicidade de seu nome, todo processo tornou-se um plug de sua melodia. Tanto técnica como economicamente, a publicidade e a indústria cultural se confundem (ADORNO; HORKHEIMER, 1985, p. 135).

Para finalizar, citamos as ideias de Habermas (1990), que afirma não haver nada mais moderno do que criticar e apontar os limtes da modernidade e isso não significa identificar uma ruptura social e cultural, mesmo que haja um desejo implícito de ruptura no sentido da possibilidade de superação das críticas anunciadas. O autor completa afirmando que a própria 
modernidade nasceu como crítica sobre ela mesma, a partir da obra de Hegel (1770 1830), que identificou na filosofia kantiana um marco de ruptura entre a idade média e a modernidade. Pelo que argumentamos até aqui, não basta adotar o prefixo "pós" e criticar a modernidade para que haja uma ruptura social e cultural concreta. Portanto, concluimos que a utilização da expressão pós-modernidade não apresenta fundamentos que justifiquem a sua utilização na tese apresentada, apesar de concordarmos com grande parte do conjunto das críticas que a autora sistematizou em sua pesquisa, também reconhecendo a importância de uma discussão como essa para o aprofundamento das reflexões sobre a mídia no campo da Educação Física.

\section{REFERÊNCIAS}

ADORNO, Theodor W.; HORKHEIMER, Max. Dialética do esclarecimento: fragmentos filosóficos. Rio de Janeiro: J. Zahar, 1985.

BASTOS, Larissa Grandi Vaitsman. Corpografias: entre o analógico e o digital. 2008. Tese (Doutorado em Comunicação). Rio de Janeiro, Programa de Pós-Graduação em Comunicação, Universidade Federal do Rio de Janeiro.

CASTELLS, Manuel. A sociedade em rede. São Paulo (SP): Paz e Terra, 2010.

FANTIN, Monica. Mídia-Educação: conceitos, experiências, diálogos Brasil-Itália. Florianópolis: Cidade Futura, 2006.

HABERMAS, Jurgen. O discurso filosófico da modernidade. Lisboa: Dom Quixote, 1990. ROUANET, Sergio Paulo. As razoes do iluminismo. São Paulo: Companhia das Letras, 1987.

\title{
BODIES, IDENTITY AND PHOTOGRAPHY IN THE MODERNITY DIGITAL
}

\begin{abstract}
Media, photography, body and female identity are the four areas that the author of the thesis Corpografias: between analog and digital uses to reflect on the process of identity construction in post-modernity. In this context, we conducted a review of the thesis in order to open a dialogue between production of the contributions to the field of media-education, as well as questioning the use of the term postmodern to characterize contemporary society and culture.
\end{abstract}

Keywords: Media; photography; body, identity 